\section{New substrates for Achilles tendinopathy: substantial plantaris tendon or Substance P?}

Johannes L Tol

An interesting debate on the exact aetiology of pain in Achilles tendinopathy is ongoing. Contrary to an intratendinous degenerative origin of the pain, a new theory focuses on the role of the plantaris tendon. This new theory reflects a paratendinous origin of the pain with ingrowth of sensory and sympathetic nerves and release of nociceptive substances. ${ }^{1}$ Alfredson ${ }^{2}$ presents convincing evidence for the role of the plantaris tendon (see pages 1023 and 1026) which is thickened and is in close relation or invaginated to the medial Achilles tendon in $80 \%$ of the symptomatic tendons.

\section{THE PAINFUL SUBSTANCE OF DEGENERATION: P?}

Inspired by the Scandinavian pioneers, I note an exponential increase of basic and clinical research with a strong focus on clarifying the mechanism of degeneration and reversion to regenerative processes. This increased attention raises our hopes that chronic tendon injuries could finally be treated by stimulating regenerative processes. It was anticipated that conservative therapies such as eccentric training, hyperosmolar dextrose injection, glyceryl trinitrate patches, autologous and plateletrich plasma injections would all stimulate tenocyte proliferation and subsequent collagen regeneration with excellent preliminary results. However, reversing the ongoing complex process of degeneration to regeneration has proven to be too complicated and frequently insufficient. This should awaken us to be open minded for new insights and challenges.

Andersson and colleagues ${ }^{3}$ take the first step to clarify the potential for blocking the ongoing degenerative process (see page 1017). The aetiological factor Substance $\mathrm{P}$ is, in addition to its established

Correspondence to Dr Johannes L Tol, Department of Sports Medicine, The Hague Medical Centre, Burg Banninglaan, Leidschendam, The Netherlands; hanstol@hotmail.com role in nociceptive signalling, involved in the development of tendinosis. The authors demonstrate that in an animal tendinosis model, Substance P plays a crucial role in degeneration development with increased tenocyte hypercellularity and angiogenesis by stimulating vascular proliferation. Substance $\mathrm{P}$ is present in asymptomatic tendons in a low concentration and is upregulated in tendinosis. Andersson et a $\beta$ cautiously conclude that blocking of Substance P might potentially be of clinical importance. Would that be our new target and key to success?

\section{SUBSTANTIAL PLANTARIS: THE PAINFUL SUBSTRATE?}

It is refreshing to see that the focus on the main intratendinous degenerative origin of the complaints is questioned, as evidence for the substantial role of the plantaris tendon is presented in this issue. ${ }^{23}$

An invaginated and thickened plantaris tendon, closely related to the midportion Achilles tendon, is suggested to increase compression and induce reactions within the cell and matrix. ${ }^{24}$ This report is the first with such numbers and detail. Sterkenburg and Van Dijk already hypothesised that adhesions between the Achilles and plantaris tendons may cause pain by intertendinous traction on sensory nerve fibres. ${ }^{15}$ It seems volvement was confirmed by changing from a lateral to a medial incision. ${ }^{23}$ Would Columbus have had discovered America if the wind had blown towards the east instead of the west coast?

\section{IS THERE NOW SUBSTANCE TO SUBSTI- TUTE THE DEGENERATION THEORY?}

The key arguments against the underlying degenerative theory are based on the fact that the tendon itself is almost aneuronal and that even asymptomatic individuals can have degenerated tendons. ${ }^{16}$ In musculoskeletal injuries, however, there is often little correlation between tissue degeneration and pain. Chronic curious that the discovery of plantaris in- degenerative tendinopathy can be interpreted as analogous to the iceberg theory with pain representing the tip of it. Moderate intradendinous degenerative changes may be asymptomatic for long periods until increasing tendon disorganisation leads to the pain threshold being exceeded. ${ }^{7}$

\section{SUBSTRATES AS SOLUTIONS?}

With the focus on the plantaris tendon it seems, or it is at least suggestive, that there is an assumed shift from belief in regeneration of collagen tissue to just treating symptoms by denervating the responsible nerves (as in the old days). Or is that too pessimistic and can we still support the degeneration theory? Will Alfredson show us that the plantaris tendon might not have that substantial role and that its involvement should be viewed as potential additional factor to be treated?

It is a utopian idea that one substrate will bring us the complete solution of this multifactorial and complex entity: neither $\mathrm{P}$ nor plantaris. The key to management of tendinopathies will continue to be expert clinical and imaging assessment to diagnose the primary causative factors, followed by skillful execution of evidencebased treatment.

\section{Competing interests None.}

Provenance and peer review Not commissioned; internally peer reviewed.

Accepted 2 August 2011

Br J Sports Med 2011;45:1013.

doi:10.1136/bjsports-2011-090440

\section{REFERENCES}

1. van Sterkenburg MN, van Dijk CN. Mid-portion Achilles tendinopathy: why painful? An evidencebased philosophy. Knee Surg Sports Traumatol Arthrosc 2011;19:1367-75.

2. Alfredson H. Midportion Achilles tendinosis and the plantaris tendon. Br J Sports Med 2011;45:1023-5.

3. Andersson G, Backman LJ, Scott A, et al. Substance $P$ accelerates hypercellularity and angiogenesis in tendon tissue and enhances paratendinitis in response to Achilles tendon overuse in a tendinopathy model. Br J Sports Med 2011;45:1017-22.

4. Cook JL, Purdam CR. Is tendon pathology a continuum? A pathology model to explain the clinical presentation of load-induced tendinopathy. Br J Sports Med 2009;43:409-16.

5. van Sterkenburg MN, Kerkhoffs GM, Kleipool RP, et al. The plantaris tendon and a potential role in mid-portion Achilles tendinopathy: an observational anatomical study. J Anat 2011;218:336-41.

6. Khan KM, Cook JL, Bonar F, et al. Histopathology of common tendinopathies. Update and implications for clinical management. Sports Med 1999;27:393-408.

7. Leadbetter WB. Cell-matrix response in tendon injury. Clin Sports Med 1992;11:533-78. 